Portland State University

PDXScholar

Spring 2020

\title{
Exploring an Instrumented Balance Assessment in Athletes with Acute Mild Traumatic Brain Injury Compared to Healthy Athletes and Non-Athletes
}

Bryana Popa

Portland State University

Follow this and additional works at: https://pdxscholar.library.pdx.edu/honorstheses

Part of the Sports Medicine Commons

Let us know how access to this document benefits you.

\section{Recommended Citation}

Popa, Bryana, "Exploring an Instrumented Balance Assessment in Athletes with Acute Mild Traumatic Brain Injury Compared to Healthy Athletes and Non-Athletes" (2020). University Honors Theses. Paper 921.

https://doi.org/10.15760/honors.943

This Thesis is brought to you for free and open access. It has been accepted for inclusion in University Honors Theses by an authorized administrator of PDXScholar. Please contact us if we can make this document more accessible: pdxscholar@pdx.edu. 
Exploring an Instrumented Balance Assessment in Athletes with Acute Mild Traumatic Brain Injury Compared to Healthy Athletes and Non-Athletes

by

Bryana Popa

An undergraduate honors thesis submitted in partial fulfillment of the requirements for the degree of

\author{
Bachelor of Science \\ in \\ Pre-Clinical Health Sciences
}

Thesis Committee:

Laurie A. King, Ph.D., PT, M.C.R.

Lucy Parrington, Ph.D.

Douglas N. Martini, Ph.D.

Portland State University 


\begin{abstract}
Balance deficits are common following mild Traumatic Brain Injury (mTBI) and can persist beyond the standard recovery period. Advances in wearable technologies, such as inertial measurement units (IMUs), have increased utilization of instrumented balance assessments. There are limited studies providing normative ranges for the Balance Error Scoring System (mBESS) to characterize abnormalities in people with mTBI. This thesis provides balance ranges for athletes with acute mTBI and normative control populations completing the mBESS. Testing occurred at the university athletic facility or the Balance Disorders Laboratory at Oregon Health \& Science University (OHSU) and the Veterans Affairs Portland Health Care System (VAPORHCS). Data from 102 healthy participants and 50 athletes with acute mTBI were collected. The primary outcome was the medio-lateral root-mean-square of sway (ML RMS Sway) in three mBESS stance conditions and the average ML RMS Sway of all conditions. A one-way analysis of variance (ANOVA) evaluated differences between groups. Main effects were significant for ML RMS Sway for DS, SS, and the average across all conditions. Percentiles were provided to guide team physicians and athletic trainers in assessing instrumented balance in these populations. Limitations include not assessing sex differences in ML RMS Sway and not reporting more sway measures, such as RMS Sway in the anteriorposterior (A/P) direction. Future research should collect data for non-athlete groups with acute mTBI and assess sex differences and obtain other sway measures. Providing normative data allows team physicians and athletic trainers to better determine return-to-play (RTP) and recovery timelines following an mTBI.
\end{abstract}


Keywords: modified Balance Error Scoring System (mBESS); mild Traumatic Brain Injury (mTBI); Root-mean-square (RMS); Sports Concussion Assessment Tool 3 (SCAT-3); Inertial Sensor 


\section{Acknowledgements}

With the sincerest gratitude, I would like to acknowledge my thesis advisor, Dr. Laurie King who has provided exceptional mentorship with all aspects of this project. Thank you for taking me on as a Build Exito student and welcoming me into the research world with kindness and encouragement every step of the way. I am immensely grateful to Dr. Lucy Parrington for her tremendous patience, encouragement, and expertise. Thank you for reading this document repeatedly, guiding me with probing questions throughout the writing process, encouraging me to problem solve, providing support with data analysis, and for the countless hours you have put into providing mentorship. Thank you to Dr. Douglas Martini for his incredible mentorship and commitment to my professional and research development- thank you for never failing to explain all my statistic and data analysis questions. A tremendous thank you to everyone else at the Balance Disorders Laboratory for their support including Jennifer Wilhelm, Shelby Martin, and the RA's. I would like to thank my Build Exito family including Carlos Crespo and Cohort 3 and acknowledge that without Build Exito, this research opportunity and thesis would have not been possible. Finally, I'd like to thank my family who supported me with late night hugs, food, prayers, and encouragement- I am deeply indebted to you. 


\section{Funding}

Research reported in this publication was supported by the Eunice Kennedy Shriver National Institute of Child Health \& Human Development at the National Institutes of Health (NIH) under Award Number R21HD080398 and by the National Center for Advancing Translational Sciences (NCATS) through Grant Award Number UL1TR002369. The content is solely the responsibility of the authors and does not necessarily represent the official views of the National Institutes of Health.

\section{Ethics Approval and Consent to Participate}

All participants completed written informed consent prior to testing. An investigator or research assistant verbally described the consent form and allowed time for participant to thoroughly read through consent form followed by signing and dating the form. All protocols have been approved by the Oregon Health Science University (OHSU) and VA Portland Health Care System (VAPORHCS) Institutional Review Board (IRB).

\section{Declaration of Conflicting Interests}

I have no conflict of interest to report. 


\section{Table of Contents}

Abstract..........................

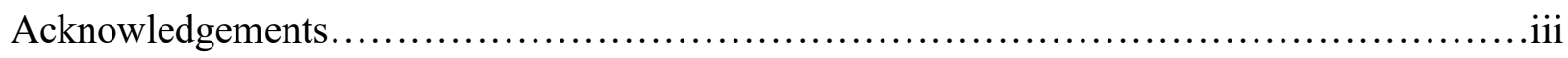

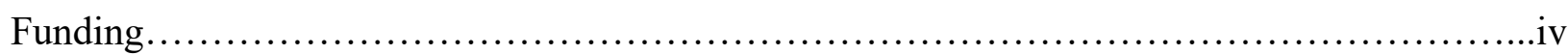

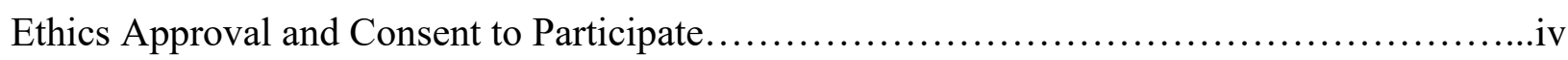

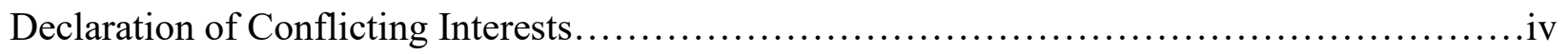

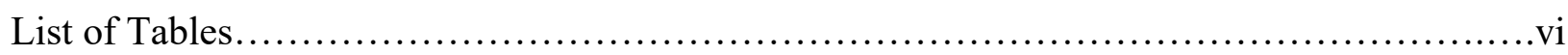

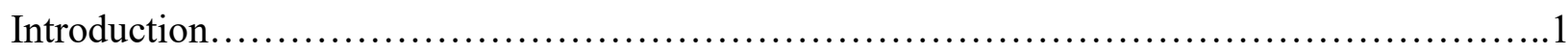

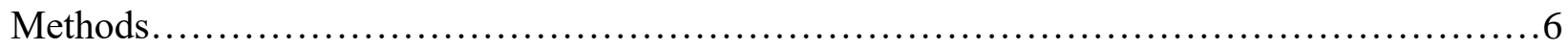

Participants............................................................6

Data Collection..........................................................

Statistical Analysis....................................................... 10

Results.................................................................... 10

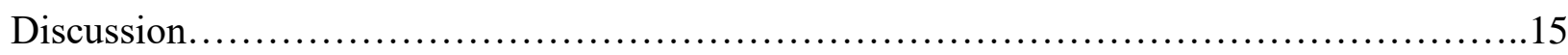

Limitations.............................................................

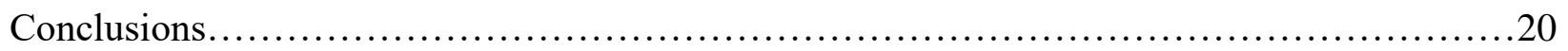

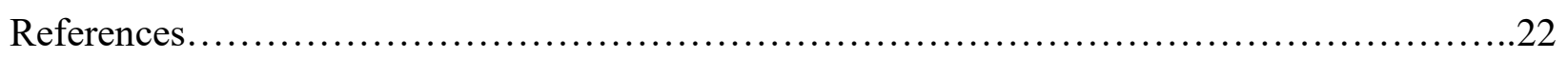




\section{List of Tables}

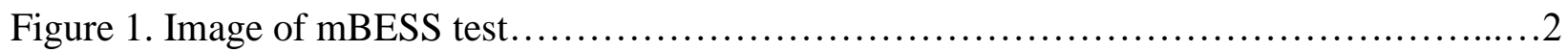

Figure 2. Medio-Lateral Direction of Movement for ML RMS Sway.........................5

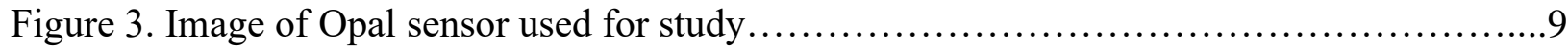

Figure 4. Placement of Opal sensor on lumbar region.................................

Table 1. Demographic data for all subjects............................................

Table 2. Percentiles for ML RMS Sway per stance condition..............................11

Table 3. Descriptive data for ML RMS Sway for athletes with acute mTBI, control athletes, and

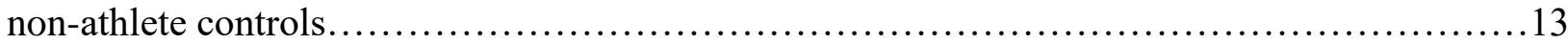

Table 4. Statistical data for between groups, within groups, and total across all stance conditions

and the average ML RMS Sway across all conditions..................................14 


\section{Introduction}

Traumatic brain injury (TBI) is one of the leading causes of death and disability in the United States. Every year 1.7 million people sustain a TBI in the United States and of these, 84\% are considered mild TBI (mTBI), or concussion (Faul et al., 2010). According to the American Congress of Rehabilitation Medicine (1993), an mTBI occurs when the onset of a traumatic impact causes disrupted brain function and is often followed by persisting symptoms. Mild TBIs have become a major public health concern and while the majority of patients recover completely and return to baseline following a mTBI, a subset of patients experience persistent symptoms (Kamins et al., 2016).

Mild Traumatic Brain Injury results in a range of neurological impairments and symptoms, including complaints of dizziness and imbalance. Balance deficits, in particular, are prevalent following an mTBI (Bernstein, 1999; Leddy et al., 2012; Levin et al., 1987). Balance is crucial for completing activities of daily function, and impaired balance can interfere with activities of daily function such as standing and walking (Wade et al., 1997). There is consensus on the importance of assessing balance in a clinical mTBI evaluation (Broglio et al., 2014; McCrory et al., 2017), however, there are known limitations.

The Balance Error Scoring System (BESS) and its abridged version, the modified BESS (mBESS), are well-known common clinical tools for balance assessment after sustaining an mTBI (Riemann et al., 1999; Guskiewicz et al., 2001; Iverson \& Koehle, 2013). The BESS involves the measurement of balance in three different stance positions (DS - feet together double stance, SS- single-leg stance, and TS - tandem stance) on two different surfaces (firm and foam) with eyes closed and hands placed on the hips (Riemann et al., 1999). Comparatively, the mBESS only involves the firm surface conditions (Iverson \& Koehle, 2013), as seen in Figure 1. 


\section{Figure 1}

Image of the mBESS test
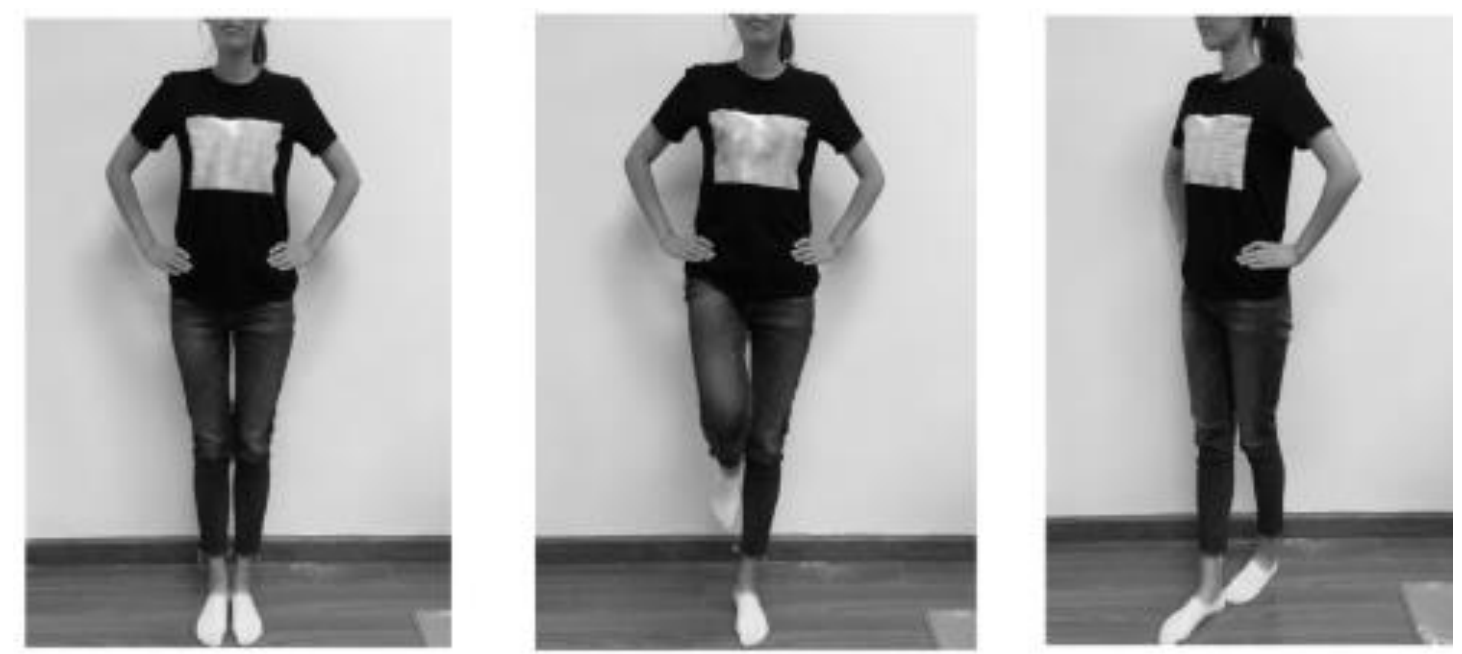

Note. Images show the mBESS test performed on a firm surface with three different stance conditions (double stance, single-leg stance, tandem stance). Participants stand for 30 seconds with eyes closed and hands placed on hips (Zhu et al., 2017). Image adapted from "Figure 1" in An Objective Balance Error Scoring System for Sideline Concussion Evaluation Using Duplex Kinect Sensors by M. Zhu, Z.Huang, C.Ma, and Y.Li, 2017, Sensors, 17(10), p.2398 (https://doi.org/10.3390/s17102398). Copyright 2017 by the authors.

Both the BESS and mBESS are rated by a clinical examiner who subjectively counts the number of errors, predefined as lifting the hands off the hips, taking a step, stumble or fall, and opening the eyes, among others (Riemann et al., 1999). While these tests are clinically accessible (Riemann \& Guskiewicz, 2000) cost-efficient (Guskiewicz et al., 2001) and easily administered, both tests are reported to have high subjectivity (Starling et al., 2015), insensitivity to mild balance impairments (King et al., 2014), as well as suffer from learning (Mulligan et al., 2013), practice (Valovich et al., 2003), and fatigue effects (Wilkins et al., 2004). These limitations have 
driven researchers to seek out alternative methods for objective balance assessment, to aid clinical decision making and tracking of mTBI recovery.

The use of instrumentation such as force plates to collect postural sway is common in laboratory research. However, these technologies have typically been limited to laboratory settings due to the need for technical expertise to administer and interpret tests (Hubble, 2015). In comparison, recent advances in wearable technologies have increased utilization and testing of inertial motion sensors as an alternative to provide objective measures of balance. This has created opportunities for the instrumentation of varying assessments and protocols. Furthermore, evidence of validity and reliability for balance measurements derived from inertial motion sensors have been found for neurological populations, including people with mild or early Parkinson's disease (Mancini et al., 2012), multiple sclerosis, (Bernhard et al., 2018; Spain et al. 2012; Sun et al. 2018) and in older adults (Doheny et al., 2012). Thus, wearable inertial motion sensors have provided the opportunity to explore balance dysfunction in other neurological populations, such as athletes with mTBI (Ghislieri et al., 2019).

For a variety of sports, high balance proficiency is essential for complex tasks and competitive athletic performance (Sahler et al., 2012; Han et al., 2015). Studies have found a significant link between poor balance and sports-related injury risk (Hrysomallis 2007, 2011). Because balance already plays an important role in athletic performance, a potential disruption of balance by an mTBI is important when considering return-to-play (RTP) timelines. Appropriate RTP timelines are still being discussed as subjective symptoms and objective outcomes vary and are at times, at odds (Parrington et al., 2019), however it is agreed that an important component of RTP is whether the athlete's balance assessments following an mTBI are not significantly different from their healthy baseline values (Dabbs et al., 2017). Few objective tests and signs 
make it difficult for team physicians and athletic trainers to determine RTP timelines for athletes. Evidence from King et al. $(2014,2017)$ suggests that the instrumentation of the mBESS provides greater diagnostic accuracy compared to the non-instrumented mBESS by reducing classification errors. Reducing classification errors allows for a more accurate assessment of balance following an mTBI. Thus, greater diagnostic accuracy would, in theory, draw clearer clinical judgements for individual readiness for RTP.

It is important for athletes to RTP at appropriate timelines, as premature RTP has potential dangers. For instance, a study by McCrea et al. (2020) found that the acute phase following an mTBI ( $\leq 10$ days) is a particularly vulnerable window for an increased risk of repeated $\mathrm{mTBI}$, along with a more serious disruption to brain function and prolonged recovery time if an mTBI is sustained during this acute stage (Guskiewicz et al., 2003). Thus, proper RTP timelines are essential. Currently, however, many RTP decisions are based upon symptomatic reporting by athletes themselves. Unfortunately, athletes, parents, and even athletic coaches may pressure premature RTP for a myriad of reasons (Kroshus et al., 2015) including misinformation about mTBIs, fear of jeopardizing career, coach, or team, and pressure to return (National Center for Injury Prevention and Control, 2015), among other reasons that accompany the culture of sporting (Sahler et al., 2012). The lack of or underreporting of symptoms points to the subjectivity and unreliability of solely symptom reporting. Furthermore, although subjective symptoms may resolve on a surface-level, underlying balance pathology may continue to exist (Guskiewicz et al., 1997). This increases the need of having objective and instrumented balance tests available for team physicians and athlete trainers to work hand-in-hand with reported symptoms. In order for objective tests to be useful for team physicians and athletic trainers, 
normative data for athletes with and without an acute mTBI must be available to help determine when a person no longer has balance problems after mTBI.

Balance consists of multiple components that can be objectively measured. An important component of balance is postural sway. The outcome measure for this thesis is medio-lateral root mean square of sway acceleration (ML RMS Sway). ML RMS Sway is a measure of the magnitude of the variability in a data signal. In the case of inertial sensors, the data signal refers specifically to the acceleration data (Neville, 2015). Medio-lateral movement, shifting from left to right, is illustrated in Figure 2, below.

\section{Figure 2}

\section{Medio-Lateral Direction of Movement for ML RMS Sway}

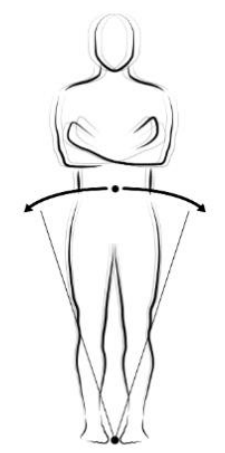

Note. Image depicts ML RMS Sway in the medio-lateral direction. Image adapted from APDM.com. (https://www.apdm.com/mobility/). Copyright 2020 by APDM Wearable Technologies.

Researchers in the area of mTBI have previously used RMS Sway as a measure of balance (Powers et al., 2014; King et al., 2017). In a study, Powers, et al. (2014) used forced plates to objectively measure balance in athletes in the acute phase after sustaining an mTBI. This study found that using RMS Sway for assessing the displacement of center of pressure 
(COP) had stronger effects in the anterior-posterior (AP) direction. Comparatively, in a later investigation, which involved some of the data used within this thesis, King et al. (2017) found that, when measuring balance, RMS Sway measured in the medio-lateral (ML) direction was the most sensitive measure for athletes with an acute mTBI. This discrepancy may be explained by the use of a force plate and the quantification of COP RMS by Powers et al. (2014) versus the quantification of RMS lumbar-sensor acceleration by King et al. (2017). For the purpose of this thesis, ML RMS Sway was used on the basis that King et al. (2017) found it to be the best discriminator for athletes with an acute mTBI when using APDM Opal sensors.

Despite the increased use of wearable sensor technologies to estimate measures of balance, there is little information to aid the interpretation of data collected. Understanding 'how much' or 'how little' someone sways in comparison with normative ranges may allow team physicians and athletic trainers to make appropriate RTP decisions. Currently, however, there are limited studies providing normative ranges for postural sway for athletic populations compared to healthy controls. Thus, the aim of this thesis was to establish normative ranges for the comparison of balance parameters among healthy athletes, healthy non-athletes, and athletes with an acute mTBI. Establishing percentile ranges for the instrumented mBESS, in particular for the ML RMS Sway, will help team physicians and athletic trainers to objectively categorize balance deficits in people as normative or prescriptive to inform RTP and rehabilitation.

\section{Methods}

\section{Participants}

This manuscript presents a secondary analysis on data collected across two separate studies that measured postural sway in athletes with an acute ( $<4$ days $)$ mTBI $(\mathrm{N}=50)$, age- 
matched control athletes (N=82) (NCT01661075, KL2TR00152), and non-athletes $(\mathrm{N}=20)$ (NCT01377454).

Athlete participants were recruited from six universities within the Portland Metropolitan Area, while non-athletes were recruited from the local community. The on-site athletic trainer referred athletes who had sustained an mTBI to the study within 24 to 48 hours following injury. Eligibility requirements for participating in the study included being 18 years of age or older and having a confirmed mTBI diagnosis from either their team clinician or a sports physician from Oregon Health and Science University (OHSU). The Sports Concussion Assessment Tool 3 (SCAT-3) is a symptom evaluation for athletes who have sustained an mTBI and allows for each person to score themselves for a list of symptoms on a scale of zero (no symptoms) to six (severe). The SCAT-3 was utilized to assess mTBIs in the athletes, with the total number of symptoms and the symptom severity score being used to quantify the symptoms reported by athletes following an acute mTBI. The healthy athlete counterparts for the study controls were athletes participating in the sports department at the same university. Athlete-controls were matched for age, sex, height, and mass.

Exclusion criteria for the participants included having a history of medical conditions interfering with cognition or mobility. Further exclusion criteria included any injury or surgery altering balance that took place 6 months prior to the study. Written research approval was obtained from each university allowing OHSU to complete research on their campuses. Nonathlete controls were included in the study if they were between 18-29 years-old, and had no or minimal cognitive impairments with a score of 0 to 8 on the Short Blessed Test. Common exclusion criteria included participants 1) having a condition that inhibits balance performance (i.e. CNS diseases, stroke, lower extremity amputation, etc.), 2) having partaken in substance- 
abuse in the past month, according to DSM-V classifications, 3) displaying disorderly behavior hindering the validity and/or safety of study sessions, 4) reporting or displaying significant pain, 5) being a pregnant female due to potential effects on balance, 6) having a history of pathological symptoms that affect the musculoskeletal, peripheral vestibular or ocular motor systems, and 7) being unable to refrain from using balance-impairing medication(s) for 24 hours prior to the testing session. Each of the studies were conducted in accordance with the Declaration of Helsinki (1964), and were approved by OHSU Institutional Review Board (IRB) and/or the Veterans Affairs Portland Health Care System (VAPORHCS) IRB. All participating study subjects received and signed informed consent forms prior to participation.

\section{Data collection}

Common demographic details collected included participant age (yrs), sex, height (m), weight $(\mathrm{kg})$, body mass index (BMI), the total number of symptoms and symptom severity, as derived by the Sports Concussion Assessment Tool 3 (SCAT-3). In each study, the instrumented mBESS was conducted as part of a gait and balance test battery. All subjects wore an Opal v1 sensor (APDM Inc., Portland, OR) placed on the posterior lumbar (L5) region to measure postural sway while performing each of the mBESS positions, as seen in Figures 1, 3 and 4. 


\section{Figure 3}

Image of Opal sensor used for this thesis (APDM)

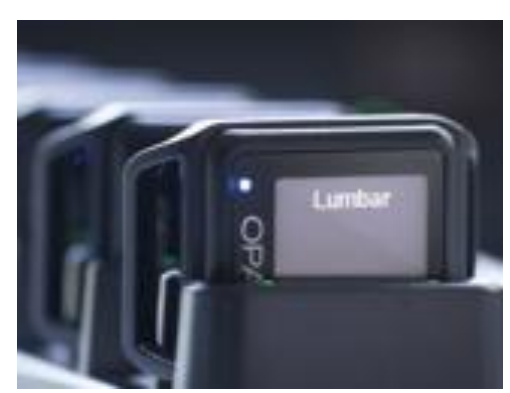

Note. Individual Opal sensor for placement on lumbar region positioned in the charging pod.

Image adapted from APDM.com. https://www.apdm.com/mobility/. Copyright 2020 by APDM Wearable Technologies.

\section{Figure 4}

Placement of Opal sensor on lumbar region (APDM)

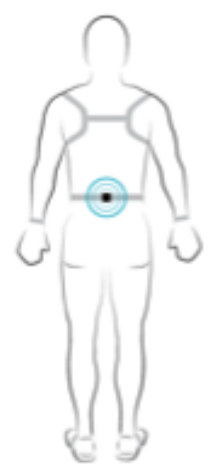

Note. Image of the placement of Opal sensor on lumbar region. Image adapted from APDM.com. https://www.apdm.com/mobility/. Copyright 2020 by APDM Wearable Technologies.

In comparison with the standard clinical mBESS procedure, the instrumented mBESS involves each stance position (DS, SS and TS) being captured for 30 seconds, rather than 20 seconds. Procedures for the instrumented mBESS were common across each study, with the exception of the location where the testing procedure took place. For the athletes with acute mTBI 
and their age-matched athlete-controls, participants were tested in a quiet well-lit hallway in their athletic training facility, while non-athlete controls were tested in a quiet clinical room either at OHSU or the VAPORHCS.

\section{Statistical Analyses}

Data were inspected for normality using histograms. Normality was first explored across cohorts (athlete with acute mTBI, athlete control, non-athlete controls) and the entire sample. Descriptive data, including percentiles for ML RMS Sway, were calculated for each group. As not all ML RMS Sway data were normally distributed, these data were log transformed for further statistical analyses. A one-way analysis of variance (ANOVA) was used to assess mBESS instrumented outcomes (ML RMS Sway per DS, SS, TS conditions and the average ML RMS Sway of the conditions), with post-hoc analyses run for multiple comparisons at an alpha level of 0.05. All data were analyzed in SPSS (SPSS Statistics 25, IBM Corporation, Armonk, NY) for analysis.

\section{Results}

Demographic data for all subjects is provided in Table 1. Athlete controls have the values of the average ML RMS Sway across all conditions that range from 70 to $348 \mathrm{~mm} / \mathrm{s}^{2}\left(5^{\text {th }}\right.$ to $95^{\text {th }}$ percentile), whereas the age-matched athletes with acute mTBI range from 83 to $377 \mathrm{~mm} / \mathrm{s}^{2}$ along the percentiles. The 18-29 non-athlete controls have ML RMS Sway values ranging from 93 to $457 \mathrm{~mm} / \mathrm{s}^{2}$. All of the percentile scores are in Table 2, for each of the stance conditions and for the average ML RMS Sway across all conditions. 


\section{Table 1}

Demographic data for all subjects

\begin{tabular}{|c|c|c|c|c|c|c|c|c|c|}
\hline & $\mathrm{N}$ & Age (yrs) & Sex & Mass (kg) & $\begin{array}{l}\text { Height } \\
\text { (m) }\end{array}$ & $\begin{array}{c}\text { SCAT } \\
\text { total \# of } \\
\text { symptoms }\end{array}$ & $\begin{array}{c}\text { SCAT } \\
\text { symptom } \\
\text { severity }\end{array}$ & $\begin{array}{l}\text { Time } \\
\text { since } \\
\text { injury }\end{array}$ & BMI \\
\hline \multicolumn{10}{|l|}{ Controls } \\
\hline \multicolumn{10}{|l|}{ Athletes } \\
\hline $18-29$ & 82 & $20.7(1.4)$ & $44 \mathrm{M} / 38 \mathrm{~F}$ & $80.2(20.6)$ & $1.8(0.1)$ & $0(0-15)$ & $0(0-18)$ & - & $24.7(18.2-41.1)$ \\
\hline \multicolumn{10}{|c|}{ Non-Athletes } \\
\hline $18-29$ & 20 & $23.8(2.4)$ & $7 \mathrm{M} / 13 \mathrm{~F}$ & $70.4(12.2)$ & $1.7(0.1)$ & $0(0-3)$ & $0(0-3)$ & - & $24.0(18.4-31.6)$ \\
\hline \multicolumn{10}{|c|}{ Acute } \\
\hline \multicolumn{10}{|l|}{ Athletes } \\
\hline $18-29$ & 50 & $20.4(1.3)$ & $35 \mathrm{M} / 15 \mathrm{~F}$ & $87.4(20.4)$ & $1.8(0.1)$ & $13(0-22)$ & $20(0-89)$ & $2.2(1.1)$ & $26.4(20.6-43.9)$ \\
\hline \multicolumn{10}{|c|}{ Note. Age, mass, height, and time since injury are presented as mean (standard deviation), while } \\
\hline \multicolumn{10}{|c|}{ the SCAT measures and BMI are presented as the median (min-max). The SCAT-3 symptom } \\
\hline \multicolumn{10}{|c|}{ evaluation produces a score of the total number of symptoms and a score of symptom severity. } \\
\hline \multicolumn{10}{|c|}{ The total number of symptoms can range from zero to the maximum number of 22 and the } \\
\hline
\end{tabular}

\section{Table 2}

Percentiles for ML RMS Sway per stance condition

\begin{tabular}{|c|c|c|c|c|c|c|c|c|c|c|c|c|c|c|c|c|c|c|c|c|c|}
\hline & \multirow[b]{2}{*}{$\mathrm{N}$} & \multicolumn{5}{|c|}{ ML_RMS_Sway_DS } & \multicolumn{5}{|c|}{ ML_RMS_Sway_SS } & \multicolumn{5}{|c|}{ ML_RMS_Sway_TS } & \multicolumn{5}{|c|}{ ML_RMS_Sway_Avg } \\
\hline & & $5^{\text {th }}$ & $25^{\text {th }}$ & $50^{\text {th }}$ & $75^{\text {th }}$ & $95^{\text {th }}$ & $5^{\text {th }}$ & $25^{\text {th }}$ & $50^{\text {th }}$ & $75^{\text {th }}$ & $95^{\text {th }}$ & $5^{\text {th }}$ & $25^{\text {th }}$ & $50^{\text {th }}$ & $75^{\text {th }}$ & $95^{\text {th }}$ & $5^{\text {th }}$ & $25^{\text {th }}$ & $50^{\text {th }}$ & $75^{\text {th }}$ & $95^{\text {th }}$ \\
\hline \multicolumn{22}{|c|}{ Controls } \\
\hline $18-29$ & 82 & 28 & 38 & 47 & 58 & 83 & 84 & 173 & 242 & 383 & 697 & 61 & 82 & 129 & 211 & 430 & 70 & 109 & 151 & 210 & 348 \\
\hline \multicolumn{22}{|c|}{ Non-Athletes } \\
\hline $\begin{array}{l}18-29 \\
\text { Acute } \\
\text { Athlet }\end{array}$ & \multicolumn{5}{|c|}{ Acute } & 87 & 125 & 246 & 427 & 582 & 1165 & & 102 & 129 & 160 & 491 & & 146 & 216 & 289 & \\
\hline $18-29$ & 50 & 35 & 48 & 66 & 91 & 218 & 121 & 193 & 325 & 469 & 810 & 64 & 88 & 140 & 215 & 349 & 83 & 134 & 182 & 244 & 377 \\
\hline
\end{tabular}

Note. This table outlines the percentile values for each stance condition, presented in $\mathrm{mm} / \mathrm{s}^{2}$. The

stance conditions are double stance (DS), single stance (SS), and tandem stance (TS). The

average ML RMS Sway for all three conditions is also presented. The percentiles include $5^{\text {th }}$, $25^{\text {th }}, 50^{\text {th }}, 75^{\text {th }}$, and $95^{\text {th }}$ ranges. 
Normative values for athletes with acute mTBI, control athletes, and control non-athlete populations are provided in Table 2. For the DS condition, the athletes with acute mTBI range from 35 to $218 \mathrm{~mm} / \mathrm{s}^{2}$ ( $5^{\text {th }}$ to $95^{\text {th }}$ percentile), whereas the age-matched athlete controls have ML RMS Sway values that range from 28 to $83 \mathrm{~mm} / \mathrm{s}^{2}$. The non-athlete controls have ML RMS Sway values ranging from 25 to $87 \mathrm{~mm} / \mathrm{s}^{2}$. For the $\mathrm{SS}$ condition, the athletes with acute mTBI have ML RMS Sway values ranging from 121 to $810 \mathrm{~mm} / \mathrm{s}^{2}$, whereas the age-matched athlete controls range from 84 to $697 \mathrm{~mm} / \mathrm{s}^{2}$. The non-athlete controls have ML RMS Sway values ranging from 125 to $1165 \mathrm{~mm} / \mathrm{s}^{2}$. For the TS condition, the athletes with acute mTBI range from 64 to $349 \mathrm{~mm} / \mathrm{s}^{2}$, whereas the age-matched athlete controls range from 61 to $430 \mathrm{~mm} / \mathrm{s}^{2}$. The non-athlete controls have ML RMS Sway values ranging from 62 to $491 \mathrm{~mm} / \mathrm{s}^{2}$.

Descriptive data are provided in Table 3. Statistical data, including the sum of squares, the degrees of freedom (df), the mean square, the F-statistic, and the significance values are provided for between groups, within groups, and/or total in Table 4. These statistics are provided for each stance condition and for the average ML RMS Sway of all conditions. A main effect was found between groups for ML RMS Sway in the DS condition $\left(\mathrm{F}_{(2,149)}=13.346 ; p<0.001\right)$. Post-hoc analysis revealed that athletes with acute mTBI [median (min-max); 66 (31-378) $\mathrm{mm} / \mathrm{s}^{2}$ ] had significantly more ML RMS Sway than the athlete controls [47 (26-134) mm/ $\left.\mathrm{s}^{2}\right]$ in the DS condition $(p<0.001)$. The non-athlete controls [65 $\left.(25-87) \mathrm{mm} / \mathrm{s}^{2}\right]$ were not significantly different to the other groups. 


\section{Table 3}

Descriptive data for ML RMS Sway for athletes with acute mTBI, control athletes and nonathlete controls

\begin{tabular}{lccccc}
\hline & N & ML_RMS_Sway_DS & ML_RMS_Sway_SS & ML_RMS_Sway_TS & ML_RMS_Sway_Avg \\
\hline $\begin{array}{l}\text { Controls } \\
\text { Athletes } \\
18-29\end{array}$ & 82 & $47(26-134)$ & $243(74-1064)$ & $129(58-794)$ & $151(60-570)$ \\
$\begin{array}{c}\text { Non-Athletes } \\
18-29\end{array}$ & 20 & $65(25-87)$ & $427(122-1180)$ & $129(61-498)$ & $216(90-460)$ \\
$\begin{array}{c}\text { Acute } \\
\text { Athletes } \\
18-29\end{array}$ & 50 & $66(31-378)$ & $325(49-909)$ & $140(46-365)$ & $182(40-430)$ \\
\hline
\end{tabular}

Note. Table above illustrates ML RMS Sway values for all cohorts aged 18-29 in all three stances in $\mathrm{mm} / \mathrm{s}^{2}$, presented as median(min-max). 


\section{Table 4}

Statistical data for between groups, within groups, and total across all stance conditions and the average ML RMS Sway across all conditions

\begin{tabular}{|c|c|c|c|c|c|c|}
\hline & & $\begin{array}{l}\text { Sum of } \\
\text { Squares }\end{array}$ & $\mathrm{df}$ & $\begin{array}{l}\text { Mean } \\
\text { Square }\end{array}$ & $\mathrm{F}$ & Sig. \\
\hline \multirow[t]{3}{*}{ ML_RMS_Sway_DS } & $\begin{array}{l}\text { Between } \\
\text { Groups }\end{array}$ & 3.981 & 2 & 1.991 & 13.346 & $p<0.001 * *$ \\
\hline & $\begin{array}{l}\text { Within } \\
\text { Groups }\end{array}$ & 22.224 & 149 & 0.149 & & \\
\hline & Total & 26.205 & 151 & & & \\
\hline \multirow[t]{3}{*}{ ML_RMS_Sway_SS } & $\begin{array}{l}\text { Between } \\
\text { Groups }\end{array}$ & 3.526 & 2 & 1.763 & 4.930 & $0.008 *$ \\
\hline & $\begin{array}{l}\text { Within } \\
\text { Groups }\end{array}$ & 53.282 & 149 & 0.358 & & \\
\hline & Total & 56.808 & 151 & & & \\
\hline \multirow[t]{3}{*}{ ML_RMS_Sway_TS } & $\begin{array}{l}\text { Between } \\
\text { Groups }\end{array}$ & 0.045 & 2 & 0.023 & 0.072 & 0.931 \\
\hline & $\begin{array}{l}\text { Within } \\
\text { Groups }\end{array}$ & 47.193 & 149 & 0.317 & & \\
\hline & Total & 47.238 & 151 & & & \\
\hline \multirow[t]{3}{*}{ ML_RMS_Sway_Avg } & $\begin{array}{l}\text { Between } \\
\text { Groups }\end{array}$ & 1.508 & 2 & 0.754 & 5.105 & $0.007 *$ \\
\hline & $\begin{array}{l}\text { Within } \\
\text { Groups }\end{array}$ & 22.012 & 149 & 0.148 & & \\
\hline & Total & 23.521 & 151 & & & \\
\hline
\end{tabular}

Note. The results in the table include the sum of squares, degrees of freedom (df), mean square, F-statistic, and significance value. These data are for between groups, within groups, and total across all stance conditions and the average ML RMS Sway across all conditions. $*$ Significant at $\mathrm{p}<0.05 ; * *$ Significant at $\mathrm{p}<0.001$.

A main effect was found between groups for ML RMS Sway in the SS condition $\left(\mathrm{F}_{(2,149)}=4.930 ; p=0.008\right)$. Post -hoc analysis revealed athlete controls $\left[243(74-1064) \mathrm{mm} / \mathrm{s}^{2}\right]$ had significantly less ML RMS Sway than the non-athlete controls [427 (122-1180) $\mathrm{mm} / \mathrm{s}^{2}$ ] in the SS condition $(p=0.003)$. The athletes with acute mTBI $\left[325(49-909) \mathrm{mm} / \mathrm{s}^{2}\right]$ were not significantly different from the control groups. 
In the TS condition, ML RMS Sway was not significantly different between groups $(p=0.931)$. The athletes with acute mTBI $\left[140(46-365) \mathrm{mm} / \mathrm{s}^{2}\right]$ were not significantly different to the athlete controls [129 (58-794) $\left.\mathrm{mm} / \mathrm{s}^{2}\right]$ and non-athlete controls $\left[129(61-498) \mathrm{mm} / \mathrm{s}^{2}\right]$.

Furthermore, a main effect was found between groups for the average ML RMS Sway across conditions $\left(\mathrm{F}_{(2,149)}=5.105 ; p=0.007\right)$. Post-hoc analysis revealed that athletes with acute mTBI [182 (40-430)] had significantly more ML RMS Sway than the athlete controls [151 (60570) $\mathrm{mm} / \mathrm{s}^{2}$ ] in average ML RMS Sway across conditions $(p=0.005)$. The non-athlete controls [216 $\left.(90-460) \mathrm{mm} / \mathrm{s}^{2}\right]$ had significantly more ML RMS Sway than the athlete controls $(p=0.029)$.

\section{Discussion}

This thesis reports data from two studies that assessed balance using the instrumented mBESS. This thesis is unique in that it is the first to provide instrumented sway data across 1829 aged athletes with acute mTBI, athlete controls, and non-athlete controls. As observed in Table 2, the percentiles values $\left(5^{\text {th }}\right.$ to $\left.95^{\text {th }}\right)$ of ML RMS Sway $\left(\mathrm{mm} / \mathrm{s}^{2}\right)$ can serve as a normative reference for team physicians and athletic trainers in understanding instrumented mBESS values obtained during clinical testing, especially if the individual does not have healthy baseline values. As these data have not yet been presented, this thesis bridges a gap for team physicians and athletic trainers to better utilize and interpret values from the instrumented mBESS assessment, specifically for the athletes with acute mTBI and their healthy age-matched athlete and non-athlete counterparts.

In the DS condition, the athlete controls had less ML RMS Sway, an indication of better performance, than the athletes with acute mTBI, but were not significantly different from the non-athlete controls. In other words, when comparing data from the athletes with acute mTBI to 
the non-athlete controls in the DS condition, there is a lack of difference in ML RMS Sway leading to the conclusion that the athletes are within normative range. However, when compared to their healthy athlete counterparts, a significant difference is clear indicating abnormal ML RMS Sway data for the athletes with acute mTBI. These data can indicate that drawing conclusions across non-matched cohorts could be problematic and emphasizes the importance of comparisons across similar cohorts. Other conditions, like the SS and average of all conditions, had significant differences in ML RMS Sway between the athlete controls and non-athlete controls which also addresses the importance of considering athletic status when assessing values derived from the instrumented mBESS test. This will be further discussed in the following paragraphs.

The SS condition showed greatest variability from minimum to maximum ranges than any other condition. This may suggest that the SS condition is the most difficult condition across all groups, regardless of mTBI diagnosis. A study by Starling, et al. (2015) found that the SS condition produced high variability, even when tested in a population of non-concussed and asymptomatic elite athletes. If there is high variability in the SS condition during the asymptomatic baseline testing of nonconcussed, elite athletes, it is expected that the variability would increase even more dramatically when testing concussed, symptomatic athletes. This high degree of variability brings to question the validity, reliability, and usefulness of the SS condition, with some even arguing for the removal of the SS condition from the mBESS protocol (Starling et al., 2015). For an athletic population, additional factors may contribute to high variability when performing the SS condition. Depending on the objectives of each sport, athletes may have greater single leg balance than the non-athlete population which may affect variability in single-stance data (Hrysomallis, 2013). Inversely, athletes may have an increased 
history of musculoskeletal injuries, such as knee or ankle injuries (Han et al., 2009; Hrysomallis, 2007), making the SS condition more difficult and contributing to high variability, reducing its usefulness in providing informative data. These factors play a role in making this stance condition difficult to interpret, especially if used in isolation to other conditions. The results from this thesis support the high degree of variability found particularly in the SS condition, across all groups, as seen in Table 3.

Since this thesis study agrees with prior literature regarding the high variability of ML RMS Sway in the SS condition, this thesis suggest that the DS condition may be most effective for detecting balance abnormalities in acute mTBI. It is probable, that this is because the DS condition is least difficult to perform. Low difficulty across populations implies low variance, particularly true with the DS condition (Guskiewicz et al., 2001; Starling et al., 2015). Because the DS condition provides least variance, any abnormalities in ML RMS Sway can be more easily detected. That being said, it is important to make a distinction in DS performance during the clinical versus the instrumented version of balance assessments, whether BESS or mBESS. The detection of any balance abnormalities using the DS condition is poor in clinical balance assessments because it is easy to perform. Some have suggested the removal of the DS condition from the clinical BESS due to its low variance (Hunt et al., 2009). However, when using instrumented balance assessments, detecting abnormal deviations in ML RMS Sway in the DS condition becomes easier for assessing balance abnormalities because there is less variability (Baracks et al., 2018). According to Baracks et al. (2018), the DS condition is preferred for instrumented balance assessments. Thus, the low variance of the DS condition in instrumented balance assessments potentially makes it the most feasible condition to be assessed independently from the other conditions. Nonetheless, all stance conditions should be assessed 
clinically, so that the team physicians and athletic trainers may have a more complete picture of all the mBESS conditions in context of each other.

For the average ML RMS Sway across conditions, the athletes with acute mTBI had significantly more ML RMS Sway than the athlete controls. The non-athlete control group also had more ML RMS Sway than their athlete counterparts. This was similar to the DS condition, where the athletes with acute mTBI had significantly more ML RMS Sway than the athlete controls, however, comparatively, in the DS condition there was no significant difference between non-athlete controls and the other groups. Furthermore, because there were significant differences between the athlete controls and the non-athlete controls in the SS condition and in the average of all conditions, these findings suggest that team physicians and athletic trainers may need to account for athlete status to inform comparisons against athlete or non-athlete normative data.

Taken together, these results further support the importance of athletic status in ML RMS Sway outputs. With the average ML RMS Sway across conditions, the athletes, whether injured or not, performed better than the non-athletic controls. Like the DS condition, the average ML RMS Sway across all conditions, highlight the risk of comparing athletes with healthy, but nonathletic counterparts. Assessing the average ML RMS Sway may provide more generalized data regarding overall balance. However, the average ML RMS Sway across conditions can be affected due to the high variability in the SS condition, and should therefore be treated with all stance conditions under consideration.

A new finding of this thesis study was that athlete controls had the lowest sway across all stance conditions. Comparatively, the non-athlete controls’ ML RMS Sway was either no different to, or greater than the athletes with acute mTBI. In other words, athletes with mTBI 
either performed equal to or better than the non-athlete controls. Apart from the TS condition, the athletes with acute mTBI were consistently significantly different from the athlete controls. These findings further highlight that comparing groups without accounting for athletic status is problematic. Failing to recognize athletic status may produce inaccurate conclusions and can adversely affect RTP timelines. Specifically, these results emphasize the importance of comparing athletes with acute mTBI to their age-matched athlete controls, as well as non-athletes with acute mTBI to their age-matched non-athlete controls.

\section{Limitations}

There are some limitations to this thesis. A limitation is that the athlete group with acute mTBI had an age-matched athlete control group, whereas the non-athlete control group did not have a non-athlete group with acute mTBI. If a non-athlete group with acute mTBI was available, a more in depth-comparison could have been drawn between groups. However, non-athlete populations with acute mTBI may be more difficult to recruit, as unlike athletes, would typically not be given an immediate referral to be diagnosed by a physician and may not be present for a check-up until the initial acute stage has passed. Another limitation to this thesis is that sex was not assessed as a contributing factor to varying balance outcomes. Particularly, in younger populations, sex has been acknowledged as a contributor to balance. A study by Ozinga et al. (2018) has shown that there are age and sex differences in postural control throughout a lifetime, but is even more prevalent during childhood, adolescence, and young adulthood. Other studies by Cushman et al. (2016) and McLeod et al. (2006) have reported the role that sex has in influencing clinical BESS scores. For each defined age cohort (5-13 years of age- youth; 14 to 18 years- high school; 19-23 years- collegiate), sex differences were significant and affected clinical BESS 
scores. Furthermore, these studies suggest the intensity of sex differences decreases with age and is less prevalent in older-young adults compared to younger adults and adolescents. When adjusted for age, youth males were seen to generate increased errors on the mBESS compared to youth females. The same was generally true for the high school cohorts. Yet, in the collegiate cohorts, no sex differences were observed across any mBESS condition suggesting that sex differences in balance performance decrease with age and are least significant in collegiate athletes. Despite little to no sex differences in collegiate athletes, it still may have been helpful to examine sex in the 1829 aged cohort for this thesis. A further limitation to this thesis study may be that RMS Sway was only reported in the ML direction, but not in the $\mathrm{A} / \mathrm{P}$ direction, which may have been useful in amplifying knowledge regarding balance differences across all cohorts. Other postural sway measures including 95\% Ellipse sway area to gain more information on displacement of COP across cohorts may be useful.

\section{Conclusions}

In research, advancements in technology has allowed for the instrumentation of balance assessments following an mTBI using wearable inertial sensors. In this thesis, data were presented for three groups: athletes with an acute mTBI, athlete controls and non-athlete controls. The main findings were that (1) the non-athlete controls performed the same or worse than the athletes with acute mTBI, (2) the athletes with acute mTBI had the greatest ML RMS Sway across all conditions and (3) the largest magnitude difference in ML RMS Sway was found between the athlete controls and non-athlete controls in the SS condition, however, with regards to differences between healthy athletes and the athletes with acute mTBI, that significant difference occurred in the DS condition and the average of all conditions. The provision of normative values, as this paper provides, is a 
step towards empowering team physicians and athletic trainers to appropriately interpret and apply objective balance assessments in populations who have an mTBI in the acute phase. This thesis serves to bridge the gap for team physicians and athletic trainers to better interpret values from the instrumented mBESS assessment. 


\section{References}

APDM Wearable Technologies. (2007). Images from Comprehensive Gait \& Balance Analysis. https://www.apdm.com/mobility/

Baracks, J., Casa, D.J., Covassin, T., Sacko, R., Scarneo, S.E., Schnyer, D., Yeargin, S.W., \& Neville, C. (2018). Acute Sport-Related Concussion Screening for Collegiate Athletes Using an Instrumented Balance Assessment. Journal of athletic training, 53(6), 597-605. https://doi.org/ 10.4085/1062-6050-174-17

Bernhard, F.P., Sartor, J., Bettecken, K., Hobert, M.A., Arnold, C., Weber, Y.G., Polis, S., Margraf, N.G., Schlenstedt, C., Hansen, C., \& Maetzler, W. (2018). Wearables for gait and balance assessment in the neurological ward - study design and first results of a prospective cross-sectional feasibility study with 384 inpatients. BMC Neurology, 18(114). https://doi.org/10.1186/s12883-018-1111-7

Bernstein, D.M. (1999). Subject Review: Recovery from mild head injury. Brain Injury, 13(3), 151-172. https://doi.org/10.1080/026990599121683

Broglio, S. P., Cantu, R. C., Gioia, G. A., Guskiewicz, K. M., Kutcher, J., Palm, M., McLeod, T. C., \& National Athletic Trainer's Association (2014). National Athletic Trainers' Association position statement: management of sport concussion. Journal of athletic training, 49(2), 245-265. https://doi.org/10.4085/1062-6050-49.1.07

Dabbs, N.C., Sauls, N.M., Zayer, A., \& Chander, H. (2017). Balance Performance in Collegiate Athletes: A Comparison of Balance Error Scoring System Measures. Journal of Functional Morphology and Kinesiology, 2(3), 26. https://doi.org/10.3390/jfmk2030026

Doheny, E. P., McGrath, D., Greene, B. R., Walsh, L., McKeown, D., Cunningham, C., Crosby, L., Kenny, R. A., \& Caulfield, B. (2012). Displacement of centre of mass during quiet standing assessed using accelerometry in older fallers and non-fallers. Conference proceedings: ... Annual International Conference of the IEEE Engineering in Medicine and Biology Society. IEEE Engineering in Medicine and Biology Society. Annual Conference, 2012, 3300-3303. https://doi.org/10.1109/EMBC.2012.6346670

Faul, M., Xu, L., Wald, M.M., \& Coronado, V.G. (2010). Traumatic Brain Injury in the United States: Emergency Department Visits, Hospitalizations and Deaths, 2002-2006. Centers for Disease Control and Prevention; National Center for Injury Prevention and Control. Atlanta, GA.

Ghislieri, M., Gastaldi, L., Pastorelli, S., Tadano, S., \& Agostini, V. (2019). Wearable Inertial Sensors to Assess Standing Balance: A Systematic Review. Sensors, 19(19), 4075. https://doi.org/10.3390/s19194075

Guskiewicz, K.M., McCrea, M., Marshall, S.W., Cantu, R.C., Randolph, C., Barr, W., Onate, J.A., Kelly, J.P. (2003). Cumulative effects associated with recurrent concussion in 
collegiate football players: the NCAA Concussion Study. Journal of American Medical Association, 290(19), 2549-2555. https://doi.org/10.1001/jama.290.19.2549

Guskiewicz, K.M., Riemann, B.L., Perrin, D.M., Nashner, L.M. (1997). Alternative Approaches to the Assessment of Mild Head Injury in Athletes. Medical Science Sports Exercise, 29(7), 213-221. https://doi.org/10.1097/00005768-199707001-00003

Guskiewicz, K.M., Ross, S.E., \& Marshall, S.W. (2001). Postural Stability and Neuropsychological Deficits After Concussion in Collegiate Athletes. Journal of athletic training, 36(3), 263-273.

Han, J., Anson, J., Waddington, G., Adams, R., \& Liu, Y. (2015). The Role of Ankle Proprioception for Balance Control in relation to Sports Performance and Injury. BioMed research international, 2015, 842804. https://doi.org/10.1155/2015/842804

Hrysomallis C. (2011). Balance ability and athletic performance. Sports medicine (Auckland, N.Z.), 41(3), 221-232. https://doi.org/10.2165/11538560-000000000-00000

Hrysomallis C. (2013). Injury incidence, risk factors and prevention in Australian rules football. Sports medicine (Auckland, N.Z.), 43(5), 339-354. https://doi.org/10.1007/s40279-013-0034-0

Hrysomallis C. (2007). Relationship between balance ability, training and sports injury risk. Sports medicine (Auckland, N.Z.), 37(6), 547-556. https://doi.org/10.2165/00007256-200737060-00007

Hubble, R.P., Naughton, G.A., Silburn, P.A., \& Cole, M.H. (2015). Wearable sensor use for assessing standing balance and walking stability in people with Parkinson's disease: a systematic review. Plos One, 10(4). https://doi.org/10.1371/journal.pone.0123705

Hunt, T. N., \& Ferrara, M. S. (2009). Age-related differences in neuropsychological testing among high school athletes. Journal of athletic training, 44(4), 405-409. https://doi.org/10.4085/1062-6050-44.4.405

Iverson, G. L., \& Koehle, M. S. (2013). Normative data for the balance error scoring system in adults. Rehabilitation research and practice, 2013, 846418. https://doi.org/10.1155/2013/846418

Kamins, J., Bigler, E., Covassin, T., Henry, L., Kemp, S., Leddy, J. J., Mayer, A., McCrea, M., Prins, M., Schneider, K. J., McLeod, T. C., Zemek, R., \& Giza, C. C. (2016). What is the physiological time to recovery after concussion? A systematic review. British journal of sports medicine, 51(12), 935-940. https://doi.org/10.1136/bjsports-2016-097464

Kay, T., Harrington, D.E., Adams, R., Anderson, T., Berrol, S., Cicerone, K., Dahlberg, C., Gerber, D., Goka, R., Harley, P., Hilt, J., Horn, L., Lehmkuhl, D., \& Malec, J. (1993). Definition 
of mild traumatic brain injury. American Congress of Rehabilitation Medicine. https://acrm.org/wp-content/uploads/pdf/TBIDef_English_10-10.pdf

King, L. A., Horak, F. B., Mancini, M., Pierce, D., Priest, K. C., Chesnutt, J., Sullivan, P., \& Chapman, J. C. (2014). Instrumenting the balance error scoring system for use with patients reporting persistent balance problems after mild traumatic brain injury. Archives of physical medicine and rehabilitation, 95(2), 353-359.

https://doi.org/10.1016/j.apmr.2013.10.015

King, L. A., Mancini, M., Fino, P. C., Chesnutt, J., Swanson, C. W., Markwardt, S., \& Chapman, J. C. (2017). Sensor-Based Balance Measures Outperform Modified Balance Error Scoring System in Identifying Acute Concussion. Annals of biomedical engineering, 45(9), 2135-2145. https://doi.org/10.1007/s10439-017-1856-y

Kroshus, E., Baugh, C. M., Daneshvar, D. H., Stamm, J. M., Laursen, R. M., \& Austin, S. B. (2015). Pressure on Sports Medicine Clinicians to Prematurely Return Collegiate Athletes to Play After Concussion. Journal of athletic training, 50(9), 944-951. https://doi.org/10.4085/1062-6050-50.6.03

Leddy, J. J., Sandhu, H., Sodhi, V., Baker, J. G., \& Willer, B. (2012). Rehabilitation of Concussion and Post-concussion Syndrome. Sports health, 4(2), 147-154. https://doi.org/10.1177/1941738111433673

Levin, H. S., Mattis, S., Ruff, R. M., Eisenberg, H. M., Marshall, L. F., Tabaddor, K., High, W. M., Jr, \& Frankowski, R. F. (1987). Neurobehavioral outcome following minor head injury: a three-center study. Journal of neurosurgery, 66(2), 234-243. https://doi.org/10.3171/jns.1987.66.2.0234

Mancini, M., Salarian, A., Carlson-Kuhta, P., Zampieri, C., King, L., Chiari, L., \& Horak, F. B. (2012). ISway: a sensitive, valid and reliable measure of postural control. Journal of neuroengineering and rehabilitation, 9, 59. https://doi.org/10.1186/1743-0003-9-59

McCrea, M., Broglio, S., McAllister, T., Zhou, W., Zhao, S., Katz, B., Kudela, M., Harezlak, J., Nelson, L., Meier, T., Marshall, S.W., \& Guskiewicz, K.M (2020). Return to play and risk of repeat concussion in collegiate football players: comparative analysis from the NCAA Concussion Study (1999-2001) and CARE Consortium (2014-2017). British Journal of Sports Medicine, 54, 102-109.

McLeod, T.C., Barr, W.B., McCrea, M., \& Guskiewicz, K.M. (2006). Psychometric and Measurement Properties of Concussion Assessment Tools in Youth Sports. Journal of athletic training, 41(4), 399-408.

McCrory, P., Meeuwisse, W., Dvořák, J., Aubry, M., Bailes, J., Broglio, S., Cantu, R. C., Cassidy, D., Echemendia, R. J., Castellani, R. J., Davis, G. A., Ellenbogen, R., Emery, C., Engebretsen, L., Feddermann-Demont, N., Giza, C. C., Guskiewicz, K. M., Herring, S., Iverson, G. L., Johnston, K. M., ... Vos, P. E. (2017). Consensus statement on 
concussion in sport-the $5^{\text {th }}$ international conference on concussion in sport held in Berlin, October 2016. British journal of sports medicine, 51(11), 838-847.

https://doi.org/10.1136/bjsports-2017-097699

Mulligan, I. J., Boland, M. A., \& McIlhenny, C. V. (2013). The balance error scoring system learned response among young adults. Sports health, 5(1), 22-26.

https://doi.org/10.1177/1941738112467755

National Center for Injury Prevention and Control, Centers for Diseases Control and Prevention. (2015). Concussion at Play: Opportunities to Reshape the Culture Around Concussion. https://www.cdc.gov/headsup/pdfs/resources/concussion_at_play_playbook-a.pdf

Neville, C., Ludlow, C., \& Rieger, B. (2015). Measuring postural stability with an inertial sensor: validity and sensitivity. Medical devices (Auckland, N.Z.), 8, 447-455. https://doi.org/10.2147/MDER.S91719

Ozinga, S. J., Linder, S. M., Koop, M. M., Dey, T., Figler, R., Russman, A. N., So, R., Rosenthal, A. H., Cruickshank, J., \& Alberts, J. L. (2018). Normative Performance on the Balance Error Scoring System by Youth, High School, and Collegiate Athletes. Journal of athletic training, 53(7), 636-645. https://doi.org/10.4085/1062-6050-129-17

Parrington, L., Fino, P. C., Swanson, C. W., Murchison, C. F., Chesnutt, J., \& King, L. A. (2019). Longitudinal Assessment of Balance and Gait After Concussion and Return to Play in Collegiate Athletes. Journal of athletic training, 54(4), 429-438. https://doi.org/10.4085/1062-6050-46-18

Powers, K. C., Kalmar, J. M., \& Cinelli, M. E. (2014). Recovery of static stability following a concussion. Gait \& posture, 39(1), 611-614. https://doi.org/10.1016/j.gaitpost.2013.05.026

Riemann, B.L., Guskiewicz, K.M., \& Shields, E.W. (1999). Relationship between Clinical and Forceplate Measures of Postural Stability. Journal of sport rehabilitation, 8(2), 71-82. https://doi.org/10.1123/jsr.8.2.71.

Riemann, B. L., \& Guskiewicz, K. M. (2000). Effects of mild head injury on postural stability as measured through clinical balance testing. Journal of athletic training, 35(1), 19-25.

Sahler, C. S., \& Greenwald, B. D. (2012). Traumatic brain injury in sports: a review. Rehabilitation research and practice, 2012, 659652. https://doi.org/10.1155/2012/659652

Spain, R. I., St George, R. J., Salarian, A., Mancini, M., Wagner, J. M., Horak, F. B., \& Bourdette, D. (2012). Body-worn motion sensors detect balance and gait deficits in people with multiple sclerosis who have normal walking speed. Gait \& posture, 35(4), 573-578. https://doi.org/10.1016/j.gaitpost.2011.11.026 
Starling, A. J., Leong, D. F., Bogle, J. M., \& Vargas, B. B. (2015). Variability of the modified Balance Error Scoring System at baseline using objective and subjective balance measures. Concussion (London, England), 1(1), CNC5. https://doi.org/10.2217/cnc.15.5

Sun, R., Moon, Y., McGinnis, R. S., Seagers, K., Motl, R. W., Sheth, N., Wright, J. A., Ghaffari, R., Patel, S., \& Sosnoff, J. J. (2018). Assessment of Postural Sway in Individuals with Multiple Sclerosis Using a Novel Wearable Inertial Sensor. Digital biomarkers, 2(1), 110. https://doi.org/10.1159/000485958

Valovich, T. C., Perrin, D. H., \& Gansneder, B. M. (2003). Repeat Administration Elicits a Practice Effect With the Balance Error Scoring System but Not With the Standardized Assessment of Concussion in High School Athletes. Journal of athletic training, 38(1), 51-56.

Wade, D.T., Crawford, S., Wenden, F.J., King, N.S., \& Moss, N.E. (1997). Does routine follow up after head injury help? A randomized controlled trial. Journal of Neurology, Neurosurgery, \& Psychiatry, 62(5), 478-484. https://doi.org/10.1136/jnnp.62.5.478

Wilkins, J.C., McLeod, T.C., Perrin, D.H., \& Gansneder, B.M. (2004). Performance on the Balance Error Scoring System Decreases After Fatigue. Journal of athletic training, 39(2), 156-161.

Zhu, M., Huang, Z., Ma, C., \& Li, Y. (2017). An Objective Balance Error Scoring System for Sideline Concussion Evaluation Using Duplex Kinect Sensors. Sensors (Basel, Switzerland), 17(10), 2398. https://doi.org/10.3390/s17102398 